\title{
Aspects of Sustainability in the Design Elements of Traditional Jordanian Houses
}

\author{
Yaman Sokienah
}

Faculty of Fine Arts, Yarmouk University, Irbid, Jordan

Received September 5, 2020; Revised October 29, 2020; Accepted November 20, 2020

\section{Cite This Paper in the following Citation Styles}

(a): [1] Yaman Sokienah, "Aspects of Sustainability in the Design Elements of Traditional Jordanian Houses," Civil Engineering and Architecture, Vol. 8, No. 6, pp. 1194 - 1201, 2020. DOI: 10.13189/cea.2020.080604.

(b): Yaman Sokienah (2020). Aspects of Sustainability in the Design Elements of Traditional Jordanian Houses. Civil Engineering and Architecture, 8(6), 1194 - 1201. DOI: 10.13189/cea.2020.080604.

Copyright $\mathrm{C} 2020$ by authors, all rights reserved. Authors agree that this article remains permanently open access under the terms of the Creative Commons Attribution License 4.0 International License

\begin{abstract}
Architecture reflects the lifestyle and the culture of the society. It shows how people are living in a particular community. One perceives the traditional architecture of any region where one can see the simplicity of this architecture and the smart usage of the surrounding environment materials. This study aims to explore traditional architecture in Jordan by studying building sites, space planning of the interior space, and building materials to understand the sustainability factors implemented in the traditional architecture in Jordan. Three traditional houses in the city of Irbid-Jordan were observed and analyzed through the building site, space planning of the interior space, and building materials used. The analysis has shown that many sustainable factors and methods were implemented in the traditional houses in Irbid city. Considering the age of those buildings, the builder did not have an in-depth knowledge of sustainability concepts, and they were working based on their experience and climate knowledge. This study's results can help create an index of sustainability for traditional architectural heritage, which will enhance the process of creating sustainable buildings without losing the place identity and staying in the same cultural context.
\end{abstract}

Keywords Traditional Architecture, Sustainability, Interior Design, Design Heritage, Design Identity

\section{Introduction}

The architecture reflects the lifestyle and the culture of the society. It shows how people are living in a particular community [1]. One perceives the traditional architecture of any region where it can be seen the simplicity of this architecture and the smart usage of the surrounding environment materials. One can notice that traditional architecture is being demolished and abandoned due to many reasons that affect the world's architectural style.

There is no doubt that Architecture is our most significant physical symbol of the community's idea of our confidant way to express the original form of our belief in the conception of common ground. Buildings also stand as evidence of the power of memory, humanity, and community [2].

Architecture is involved in many life sectors in any society. These sectors are like the environment, economics, and technologies. The sector that reflects any civilization's architecture reflects the culture, tradition, and lifestyle of that civilization. The architecture also makes the diversity of architectural styles worldwide because of the differences between society's cultures [3]. We can see any society's architectural style in every space they created, like houses, stores, and sacred spaces.

Traditional architecture may stay closer to our soul than other types of architecture because it has our mentality and our quality of life. While Jordan still preserves its traditional architecture on a medium-scale. This research investigates and gains insights into these traditional houses in Jordan to better understand this type of architecture and its relationship with sustainability.

As the concept of sustainable design and green building is still developing and trending around the globe, it has been clear that green buildings concepts enhance the chance of creating sustainable and more energy-efficient 
spaces through several aspects of sustainable design such as the integrated process and building materials [4]-[6]. As the importance of sustainable and green building awareness rises, there is a weak response of research on the sustainability of traditional architecture in Jordan. Traditional architecture has its manifestation as a valuable aspect of any culture. Understanding the sustainability aspects in it will increase this value and its importance.

This study investigated the sustainability methods practiced in traditional houses in Jordan. Sustainability is a critical issue in this era. Since sustainability is a trending topic and traditional architecture, this study aims to raise awareness about sustainability and the importance of conserving traditional architecture due to its benefits to the environment.

\section{Literature Review}

\subsection{Sustainability}

The construction process is full of aspects that directly and indirectly impact human health, the environment, and resources [1]. Those are one of the many aspects that sustainability is being studied and developed which is to reduce the impact of the construction process on human health, the environment, and the resources in regards to the three main aspects of sustainability, i.e., social, economic, and environmental aspects [1].

Where architecture and design are an integral part of any society, sustainability plays a vital role in supporting present and future users of any space to maintain resources for future occupant and maintain healthy spaces for them [7], [8]. According to the United States Green Building Council (USGBC), sustainability can be achieved through seven main categories or aspects as follows:

- Location and transportation

- Sustainable sites

- Water efficiency

- Energy and atmosphere

- Materials and resources

- Indoor air quality

The mentioned categories correlated with most, if not all, of the process and parts of constructing a building. Therefore, covering those categories and their aspects would end in constructing an almost complete sustainable environment. However, when trying to analyze existing buildings, mainly traditional buildings, it would be hard to achieve all of the sustainability aspects in the context of the major categories that can be found in different sustainability rating systems.

\subsection{Traditional Jordanian Architecture}

Traditional architecture represents a specific period and creates a connection between the present and the past and history[9]. It represents the social life and the legacy of society and its relationship with the natural environment. [10].

The traditional Jordanian house is an excellent example of the harmonious way of design according to the Islamic and Ottoman architecture style [11]. Besides, Traditional Houses are one of the ancient architectural arts that reflect the development of civilization in Jordan's history, and they witnessed a critical event that characterized the Jordanian identity and modern Jordan [12]. Most of the traditional buildings are located in a few Jordan cities, like Amman, Irbid, and Alsalt. The builders were coming from neighboring towns like Nablus, Beirut, and Damascus [11].

Most of the houses consisted of two floors, and the main character of the Jordanian homes was coming from the simple elegance and confidant design. Such houses were built using stones and mud, the old red stone that was being brought from the area of "Ghafar valley" in the southwestern area of Irbid [12]. The advantages of this mud are that it contains straw mixed with mud to increase the construction's strength and clay blocks cohesion [10]. Some of the buildings were built on the style of using arches in the Ottoman period (Figure 1), then after putting the wooden bridges, they put clay mixed with straw on the roof [13].

The houses were warm in winter and cool in summer. One of the essential characteristics of traditional houses is the high roofs from the inside and the walls' large thickness $(0.6-1 \mathrm{~m})$ [15]. On the other hand, doors and windows were built in the form of arcs to reduce the pressure on the doors and windows because they did not use iron and metal at that time in the building process [13]. After finishing the construction part, there was a new process of covering the mud walls by using white stone, which is rounded and mixed with water [15]. Besides, the traditional Jordanian architecture carefully considered the aesthetic of the designs that create original development architecture [14].

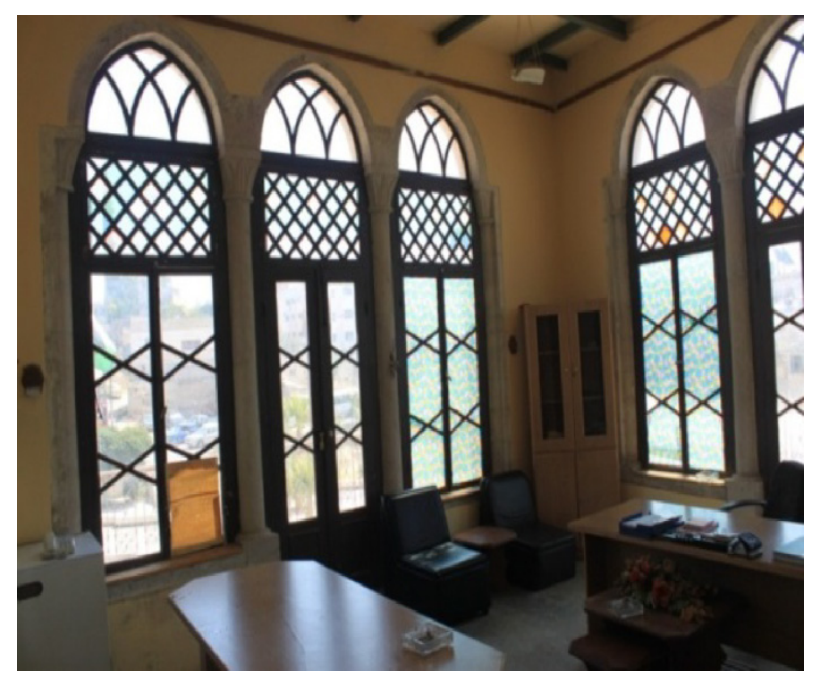

Figure 1. Using the arch shape in doors and windows in Nabulsi House 
The traditional houses in Jordan were usually built according to Islamic architecture and by adding some of the modern architectural styles from the other type of architecture. This gave the traditional Jordanian houses a unique architectural design [15]. The traditional Jordanian houses were also established and based on a series of sustainable principles, such as using the materials from the surroundings and the local environment.

\subsection{The Main Elements of the Traditional Houses in Irbid}

In Irbid, old houses had their slots (wall closets) in the walls used to save the manually processed food [12]. Moreover, to save money (which was earned by the farmer in the harvest period in the summer) also there is a special place to put the furniture, blankets, and carpets used to cover the Flooring in winter. Also, a jar was in the corner of the house used to store water in it [13].

While the house square was used sometimes for breeding cattle and birds and a water well to collect rainwater through this square through the canal, which gets to the wall, there is the build toilet unit, and a place for the ovens to produce bread is available. Large houses had their hospitality, and guesthouses separated from the house [13]. The house was surrounded by a wall of stone and mud containing a sizable main entrance in the form of arches and small openings and doors [15].

\section{Case Studies}

\subsection{Arar Museum (House)}

This house (which is now in a museum) was built on the south side of Irbid's hill in approximately 1890 by Mr. Saleh Al-Mustafa Al-Tal, Arar's father. Several stages took place in building the house, and the construction was completed in 1905. The final construction consisted of five rooms, two guest rooms, and a terrace that could host nearly three hundred people. The floor itself is black granite [16][15]. The house style emulates the Syrian style, which was popular in the first years of the twentieth century. This style employs white and black stone [15]. The house was used as a personal residence by the owner for a while, and on the eastern side of the house reside a mosque and a church, a symbol of religious respect and acceptance, which is something the people of Irbid are known for [15].

The museum has become a prominent cultural and civil landmark in the city of Irbid. Visitors can find pictures, papers, and various research papers about the life of the poet Arar. Within the museum, one can find and see a collection of memories, and a popular place to visit as it is a witness to the creative stamp of Jordan's most celebrated poet [13]. Since many activities are held in the museum, it has also become in the service of Irbid's cultural and art movements. Among such activities are poetry and literature nights, art galleries, and Arar's Annual Poetry Festival [13]. The museum has now been part of the Ministry of Culture.

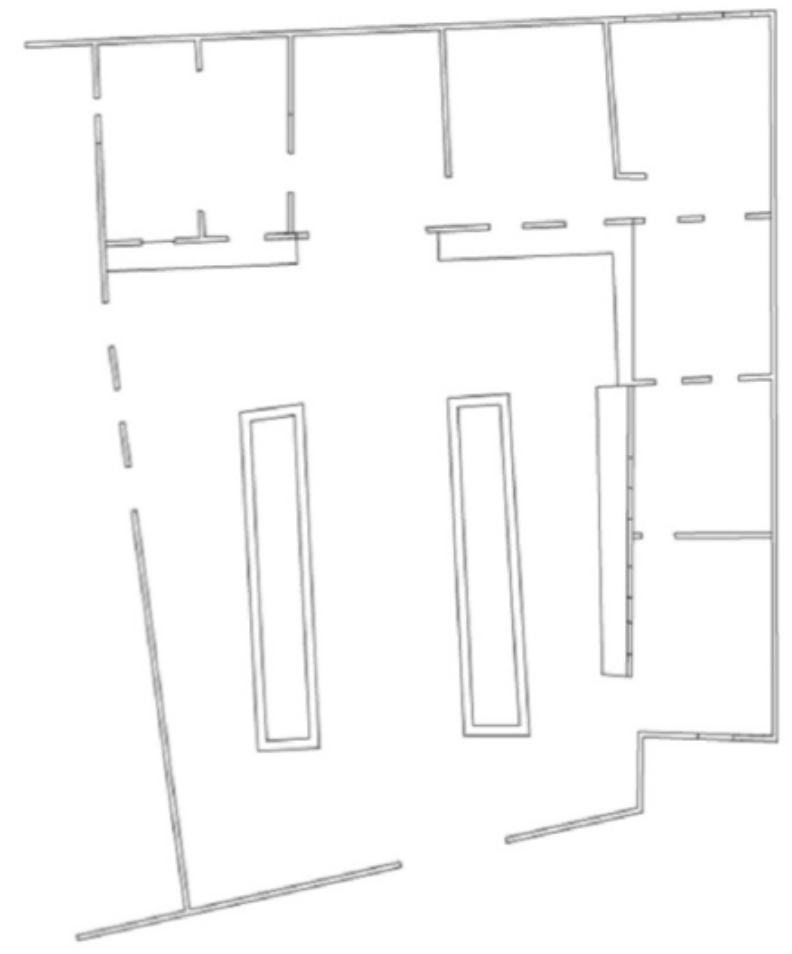

Figure 2. Arar house Plan. (Irbid Municipality, The Cultural Center)

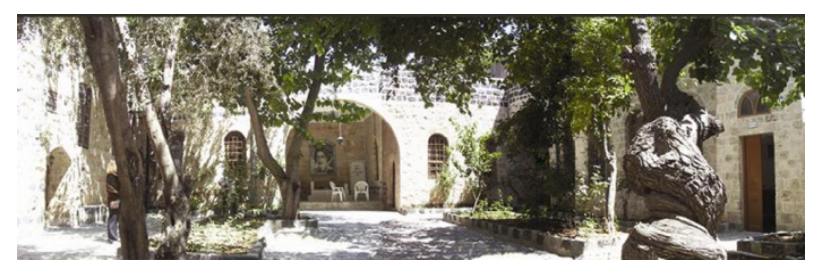

Figure 3. Arar house. (Irbid Municipality, The Cultural Center)

\subsection{Nabulsi House}

Now we turn to another critical house in Irbid. Nabulsi House is located in Irbid city downtown. Its position is on the southwestern corner of the garden Foara and surrounded by two main streets from both sides. The size of the land is about $(289 \mathrm{~m} \mathrm{2})$. The ground floor area is around $(212.2 \mathrm{~m} 2)$, the first- floor area is about (125.37 $\mathrm{m} 2)$, while the interior yard area is $(79.69 \mathrm{~m} 2)$ [13].

Mr. Ismail Nabulsi owns the house. Nabulsi is one of the most influential families in Irbid, whose roots are from Syria, and they were working in trading [13]. The house was built at the beginning of the first half of the twentieth century, roughly about 1922 [13]. The building has two floors; both of them were used as living areas. Two main streets surround the house: the eastern side (Foara St.) and the western side (Barha St.). The building has an open 
yard inside it like the old Syrian houses, where the building takes three sides of the yard [13].

Through the studying of the building's history and its consecutive uses, it has been noticed that the building was used later as a school after it was built. According to that, some modifications were made to fit the new uses [13]. A room was redesigned on the ground floor to be a health care unit, and another one was added on the first floor. Another adjustment was made, like closing some windows on the first floor and some doors on the ground floor [13]. The building is as beautiful from the inside as it is from the outside; a facade surrounds the interior yard with its exquisite details and the arches with a well-made colored glass [13].

According to the Syrian architectural style (ground floor, first floor, and an interior yard in the middle) [15], it has multiple aesthetics like the sculptured stone on the exterior facade and colored glass on the interior and exterior windows. While the interior yard has a high lemon tree with a beautiful fountain [15], the building has four entrances; three of them are on the eastern side, but they are closed now. The fourth entrance is on the southern side of the building and is the one that is being used [12]. The building has two units separated by stairs making two different houses, one of them is on the ground floor, and the other is on the first floor [12].

Through analyzing the style and the technique of the exterior building and the different geometric forms of the top windows, it has been clear that this building was built in successive periods [12]. The ground floor was built in one period, and the top floor was built in two phases: the first southern side and the eastern side holding suits [12]. The southern entrance opens in one of the rooms that lead to the interior yard. The main entrance on the eastern side leads to the stairs and two separate accesses, one of them is for the reception room connected to the rest of the house by an interior door. The other access opens to another reception room. [12]

On the one hand, the ground floor contains three rooms: the southern unit has three rooms, two of them are reachable from the interior yard, and they were changed to be bathrooms later [12]. The middle room, where the main entrance is on the southern side, the third room is located on the southeastern side (reception room).

Furthermore, it is the only room with its original Syrian flooring materials, and probably other rooms had the same flooring materials too [12]. While the eastern unit is separated from the southern unit by stairs (main entrance), it contains three rooms: western doors and window openings are facing the garden [12]. A room in the northern unit has a node opened to the garden by a semi-circle arch. It should be noted that the doors and windows of all these rooms have a rectangular shape with an Islamic styled arch above [12].

On the other hand, the upper floor is divided into two units: southern and northern, separated by an opened air staircase (main entrance). What makes this floor special is an opened staircase that can reach the long terrace that goes all along its eastern and southern façade. Moreover, the opened staircase is supported by steel piers surrounded by steel handrails all around this floor [12]. The southern unit contains three rooms; the southeast room is a spot by its repetition design style in old Irbid housing (door with two windows, with three arches above) [12]. In the South and east side of the room, these doors and windows overlooking the garden surrounding the southern suit, a bird coming up on a concrete wall supported by steel piers, and an extremely beautiful geometric handrail surround the terrace [15].

While the northern unit on the first floor contains three rooms: the middle room has a main entrance from the outdoor corridor built as an open-air terrace, connecting two units looking at an outdoor garden on the ground floor [12]. It has a door and two windows to the left and right sides of the door and makes three arches on both sides: eastern and western that also have a connected terrace looking at the street from the east and west [12].

Irbid's municipality has owned this building to save it and restore it as one of the cultural and architectural landmarks in Irbid. It became one of the most critical units of the development project of Irbid's downtown. Activities of what would help to rescue this building will be selected [15]. These activities would help youth and children sectors of those who live in this city in the first place, such as arts, cultural activities directed to this category plus whoever interested in this field [12]. Therefore, among the many notions and threads of reworking, the site has attempted to employ the building as a kind of gallery and art school, due to the privilege of the wide-opened garden that could gather many different types of art exhibits in order to teach different types of art for both youth and children by those artists who visit the place [12].

The Ministry of Tourism and Antiquities has restored the building of Nabulsi house and Irbid's downtown development project. AL Nabulsi house has been submitted to the Irbid municipality as a part of a cooperation between the municipality and the ministry of tourism in 2008 [12]. 


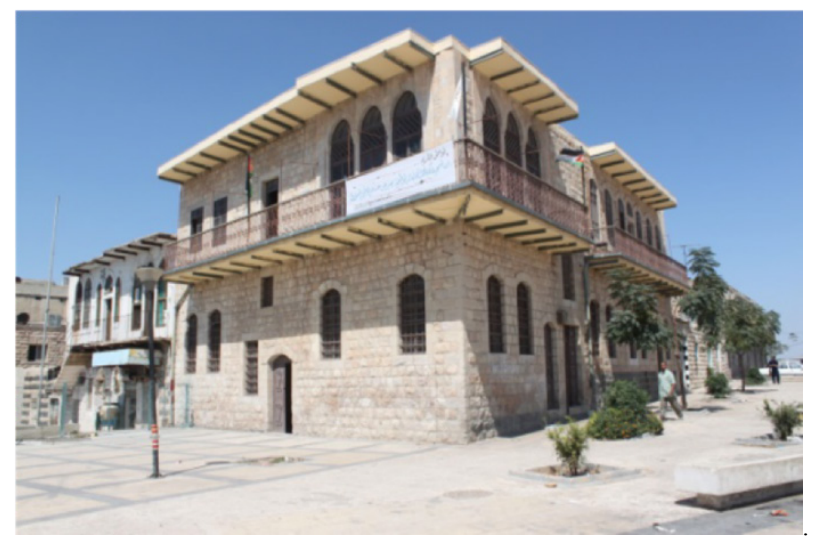

Figure 4. Nabulsi House

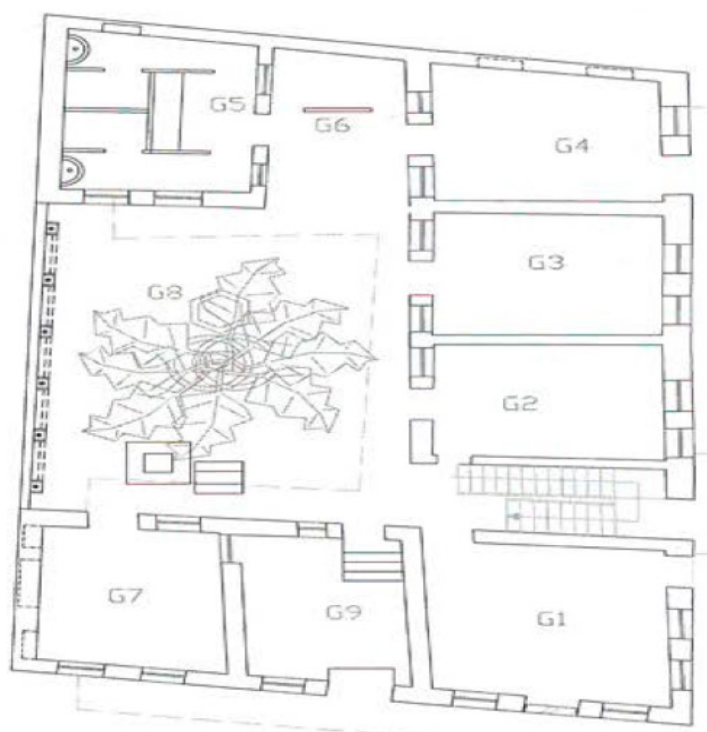

Ground Floor

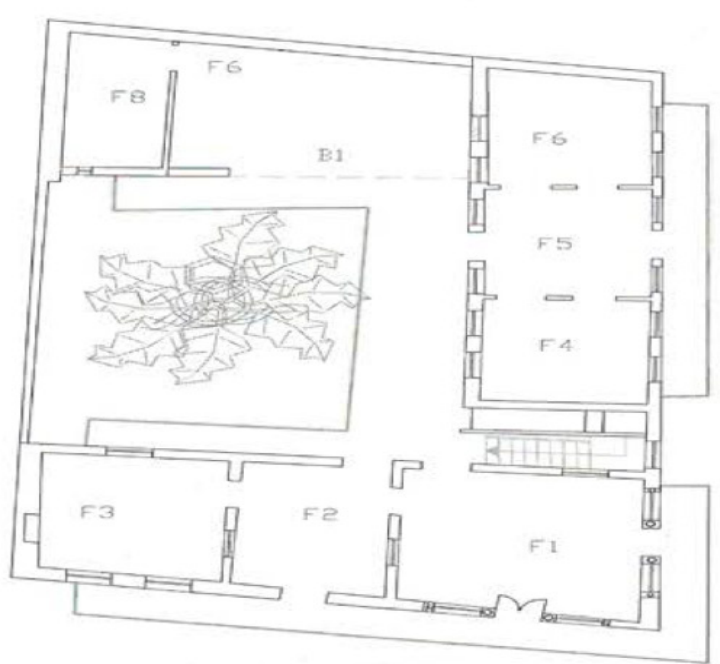

First Floor

Figure 5. Nabulsi House plans. (Irbid Municipality, The Cultural Center)

\section{Methods}

The investigation is organized into four thematic sections: [a] discussion of selected case studies based on a literature study which was described in the previous section; [b] proposed factors of sustainability of traditional architecture and design types; [c] addressing qualitative aspects of traditional design, and [d] formulating a results section, including a synthesized conceptual approach for further study and development.

Since many variables can be studied and analyzed in traditional houses and their sustainability, the researcher has focused on building sites, space planning of the interior space, and building materials. There are traditional houses in various regions in Jordan. Irbid City, located in the Northern part of Jordan, has been selected as the research area. Traditional houses constructed using wood, stone, and mud were chosen for this study. The sustainable qualities of the case studies buildings are identified by investigating the following aspects of the construction, which is also proposed and used by Yüksek \& Esin (2013):

- Building site

- Space planning of the interior space

- Building materials.

\section{Overall Analysis}

\subsection{Building Site}

The building site plays a vital role in the building's sustainable design, where it can protect the building from excessive sunlight and wind. Each region has a specific way of orienting the building based on the climate in that region. Most of the building in Irbid City faces the South to directly receive the sun and natural lighting, making solar energy gain high in the building. There are many benefits of understanding the building site where it can tell any information about the structure, where site selection is as important as the energy efficiency of the building itself [4], [18].

In terms of location, all three cases were located away from flood lands. They were also located in the Irbid city center, making it close to most utility locations such as shopping centers, retail stores, farmers, and markets. Also, in terms of transportations, being located downtown made it easy to transport by foot or by public transportations since the house's location is close to the bus stations and taxi routes.

The site's traditional houses were planted with trees open to fresh air, and the building's orientation helps get the most of the sun and wind direction, which helps in the natural temperature control inside the houses. The builders also made sure that each house's rainwater well, and a simple network ran throughout the house to collect rainwater during winter. 


\subsection{Space Planning of the Interior Space}

The layout of the interior space and how the functions are distributed throughout the space have a positive impact on reducing energy consumption in the building [17] Hence, the spaces that have significant functions and activities during the daytime usually face the southern direction to get as much as possible of the sunlight, which will reduce relaying on energy for lighting and heating. In a traditional Jordanian building, one can notice that the living rooms are usually located in the southern façade, which will reduce the energy consumption for heating and ventilating. Also, spaces like bathrooms and storage are located in different areas since they do not require much heating. Therefore, the interior space planning of traditional houses in Irbid City will be analyzed to define the main planning elements contributing to the sustainable construction methods in traditional architecture.

The walls' substantial thickness made an excellent insulator, which saved the wood that was being used in making the house warm in the summer. Also, the windows and their direction made the houses more cooling in the summer. One can always notice the center yard in the houses, which is considered a gathering space in the summertime. It also helps collect rainwater in the winter season. Again, this center yard helped create shade by planting trees and green plants, which also helped create a unique breathable space that gets and circulates fresh air throughout the house.

The builders of these houses always tried to create a space that did not have air conditioning. This can be observed by having many large windows throughout the place and having most of the house's room around the central yard that is open to fresh and outdoor air circulating the air properly.

\subsection{Building Materials}

Since building materials play an essential role in the sustainable practice of architecture and design, this study's cases were analyzed to observe the extent of the sustainable approach applied in these traditional houses. A large part of energy consumption comes from extracting the building materials and transporting them to the building site. The previous issue was overcome in the traditional houses in Irbid city through the usage of local and raw building materials [19]. This practice reduced the startup energy consumption during the construction process. Also, since the building materials are known to the builders, it was easy for them to fabricate it and build it without using extra labor.

Materials used in building traditional houses in Jordan are mostly local materials; even the labor used in constructing the houses is usually local. From the stone, cement, bricks, materials are all local building materials. As mentioned previously, in the northern part of Jordan, which is the case of Irbid, most of the stone used in the building was the basalt stone available in the area [11]. Atiyat (2015) has found that using building materials that are creating more environmentally aware structures leads to improving sustainability as a concept.

According to Alzoubi \& Almalkawi (2019), it can be noticed that the thermal insulation of the building materials used in traditional buildings has shown that it is significantly better in terms of sustainability compared to a modern building in the same region.

\subsection{Overall Sustainable Features}

Table 1 reviews the main sustainability aspects found in the case studies presented in this research and represent the most traditional buildings in Jordan. The table used was adapted from Tawfiq Almatarneh (2013).

\section{Results and Conclusions}

In this study, traditional Jordanian houses were analyzed in terms of sustainable design through three aspects, which are: building site, spaces planning of the interior space, and building materials. There were many sustainable design principles applied in these houses.

Those principles were applied based on the user experience of the region. Those strategies were mostly applied because they were simple and affordable for most people, and one can see them in most of the traditional buildings in Jordan. The importance of analyzing those strategies in traditional architecture is that those strategies are easy to implement in the new building, making them more affordable to build and maintain. Also, conventional architecture sustainable strategies will help in cooling and heating the buildings passively, which will save energy throughout the seasons.

It was noticed that the primary focus of the design of traditional houses in Irbid City was reducing the need to use energy to heat or ventilate the space. Hence, the use of the appropriate building materials such as mud, stone, and wood helped maintain the thermal comfort in the space and have many openings in the space, which improved the space's ventilation [23].

Also, the builders of traditional houses in Irbid City considered the building orientation in terms of the sun and wind direction to get as much as possible of sunlight and natural ventilation as possible. Those strategies were implemented by creating most of the openings to face the Southern direction and using the courtyard that was centralized within the building to circulate the natural air throughout the house [18].

This study's findings are consistent with existing literature in terms of traditional being sustainable to some extent and provide a better living environment without the extra equipment and energy use. Therefore, these strategies.

Like using building materials from the surrounding 
environment, having the building facing the southern direction, and adding the open spaces to the building will improve life quality while maintaining sustainability and the environmental aspects. Furthermore, those findings support the idea of traditional buildings conservation, which will support the idea of supporting the place identity of each city [24].

Application for traditional building principles in terms of interior and architectural design can be implemented in new structures such as considering rainwater collection, creating a water well, using traditional shading techniques, and implementing the courtyard concept. These methods can be easily implemented into new design concepts by maintaining and using modern building technologies.

Future research should focus on the methods of constructing a new building while considering the lessons learned in traditional architecture. This study was applied in Jordan. However, those sustainability lessons can also be found in many cultures due to the difference in climate between different regions where each region's residents build based on their climate and experience.

Table 1. Assessment sustainable design features \& strategies of Case Studies

\begin{tabular}{|c|c|c|c|c|}
\hline $\begin{array}{l}\text { Sustainable site planning } \\
\& \text { design }\end{array}$ & Water efficiency & Energy efficiency & Materials \& resources & $\begin{array}{l}\text { Indoor environmental } \\
\text { quality }\end{array}$ \\
\hline $\begin{array}{l}\text { Usage of open space at } \\
\text { the maximum level }\end{array}$ & $\begin{array}{c}\text { Rainwater collection } \\
\text { strategies }\end{array}$ & $\begin{array}{l}\text { use of traditional } \\
\text { shading methods }\end{array}$ & $\begin{array}{l}\text { using local and raw } \\
\text { building materials }\end{array}$ & $\begin{array}{l}\text { using natural lighting as } \\
\text { possible through } \\
\text { windows and courtyard }\end{array}$ \\
\hline \multirow[t]{3}{*}{$\begin{array}{l}\text { Closeness to the city } \\
\text { center and other public } \\
\text { facilities }\end{array}$} & $\begin{array}{l}\text { Water well to keep } \\
\text { collected rainwater }\end{array}$ & $\begin{array}{c}\text { increasing thermal mass } \\
\text { through the thickness of } \\
\text { the walls that were built } \\
\text { with stone }\end{array}$ & & $\begin{array}{l}\text { using shading on } \\
\text { windows to create visual } \\
\text { privacy for users }\end{array}$ \\
\hline & $\begin{array}{l}\text { Planting the open space } \\
\text { with native plants }\end{array}$ & $\begin{array}{l}\text { using local and natural } \\
\text { building materials that } \\
\text { have great U-Values }\end{array}$ & & \\
\hline & & $\begin{array}{c}\text { The building facing sun } \\
\text { direction }\end{array}$ & & \\
\hline
\end{tabular}




\section{REFERENCES}

[1] B. Salgın, Ö. Bayram, A. Akgün, and K. Agyekum, "Sustainable Features of Vernacular Architecture: Housing of Eastern Black Sea Region as a Case Study," Arts, vol. 6, no. 4, p. 11, Aug. 2017.

[2] R. P. Gabriel, "Designed as designer," ACM SIGPLAN Not., vol. 43, no. 10 , pp. 617-632, Sep. 2008.

[3] P. Oliver, Built to Meet Needs: Cultural Issues in Vernacular Architecture. Routledge, 2007.

[4] H. H. Ali and S. F. Al Nsairat, "Developing a green building assessment tool for developing countries - Case of Jordan," Build. Environ., vol. 44, no. 5, pp. 1053-1064, May 2009.

[5] J. A. Barbosa, C. Araújo, R. Mateus, and L. Bragança, "Smart interior design of buildings and its relationship to land use," Archit. Eng. Des. Manag., vol. 12, no. 2, pp. 97106, Mar. 2016.

[6] J. B. Sanjay Sneha, Koottala Biju, Alokeh Amjad, "Enhancement of Estidama Pearl Rating of a Retail store and Energy Centre using Sustainable Solutions," Int. J. Innov. Technol. Explore. Eng., vol. 8, no. 7C2, pp. 230-234, 2019.

[7] A. N. Sharvina, M. Faqih, H. R. Santosa, and A. Hayati, "Sustainable development of fishermen settlement based on cultural aspects," J. Settlements Spat. Plan., vol. 9, no. 2, pp. $117-125,2018$.

[8] R. Ssaber and B. Daryayelaal, "An Overview of the Relationship between Culture and Energy Sustainability in Traditional Iranian Architecture." 2015.

[9] N. K. A. Dwijendra, "Meru as a Hindu Sacred Building Architecture with a High Roof and Resistant to Earthquakes in Bali, Indonesia," Civil Engineering and Architecture, vol. 8, no. 3, pp. 350-358, Jun. 2020.

[10] M. Al-Asad, A. Khammash, and B. Lyons, "Old Houses of Jordan: Amman, 1920-1950," 1997.

[11] Ayman Dawood Salman1, Osamah Ibrahim Khalaf and Ghaida Muttashar Abdulsahib, 2019. An adaptive intelligent alarm system for wireless sensor networks. Indonesian Journal of Electrical Engineering and Computer Science, Vol. 15, No. 1, July 2019, pp. 142 147

[12] Y. S. Asfour, The History and Archaeology of Jordan, 2nd ed. Amman, Jordan: Al-Mujtamaa Al-Arabi, 2008.
[13] A. Rousan and A. K. Al-Rajoub, [Irbid: Archaeological, historical and heritage study], 1st ed. Amman Jordan, 2010.

[14] M. Itewi, "Towards a Modern Theory of Islamic Architecture," Aust. J. Basic Appl. Sci., vol. 1, no. 2, pp. 153-156, 2007.

[15] M. Matrouk and J. Goussous, "Recipient cognition and house identity in Jordanian architecture," Anthropologist, vol. 13, no. 4, pp. 271-281, 2011.

[16] GHAIDA MUTTASHAR ABDULSAHIB and OSAMAH IBRAHIM KHALAF, 2018. AN IMPROVED ALGORITHM TO FIRE DETECTION IN FOREST BY USING WIRELESS SENSOR NETWORKS.International Journal of Civil Engineering and Technology (IJCIET) Scope Database Indexed.Volume:9,Issue:11,Pages:369-377.

[17] İ. Yüksek and T. Esin, "Analysis of traditional rural houses in Turkey in terms of energy efficiency," Int. J. Sustain. Energy, vol. 32, no. 6, pp. 643-658, Dec. 2013.

[18] Ogudo, K.A.; Muwawa Jean Nestor, D.; Ibrahim Khalaf, O.; Daei Kasmaei, H. A Device Performance and Data Analytics Concept for Smartphones' IoT Services and Machine-Type Communication in Cellular Networks. Symmetry 2019, 11, 593

[19] M. I. Alhaddad and A. A. Alshboul, "Application of Sustainability Measures to Vernacular Architecture in Jordan A comparative study," in First International Conference on sustainability and the future, 2010, pp. 1-13.

[20] D. Atiyat, "Architecture Building Treatments in the Mediterranean Climate From an Environmental Perspective: Case Study of Amman "Jordan," J. Archit. Eng. Technol., vol. 04, no. 03, 2015.

[21] H. H. Alzoubi and A. T. Almalkawi, "A comparative study for the traditional and modern houses in terms of thermal comfort and energy consumption in Umm Qais city, Jordan," J. Ecol. Eng., vol. 20, no. 5, pp. 14-22, 2019.

[22] Prasad, S.K., Rachna, J., Khalaf, O.I., and Le, D.-N. Map matching algorithm: Real-time location tracking for smart security application. Telecommunications and Radio Engineering (English translation of Elektrosvyaz and Radiotekhnika), 2020, 79(13), pp. 1189-1203

[23] S. Roy and S. Chowdhury, "Earth as an Energy Efficient and Sustainable Building Material," Int. J. Chem. Environ. Biol. Sci. Vol., vol. 1, no. 2, pp. 248-252, 2013.

[24] D. Misırlısoy, "New Designs in Historic Context: Starchitecture vs. Architectural Conservation Principles," Civil Engineering and Architecture, vol. 5, no. 6, pp. 207 214, 2017. 